\title{
J.-J. Rousseau: A Natureza Enquanto Modelo, a Voz Interior Como Guia - Caminhos para uma Nova Compreensão da Subjetividade e da Liberdade
}

\section{J.-J. Rousseau: Nature as Model, the Inner Voice as a Guide - Pathways to a New Understanding of Subjectivity and Freedom}

\author{
ARLEI DE ESPÍNDOLA ${ }^{1}$
}

\begin{abstract}
Resumo: O meu propósito no presente texto é mostrar, de início, que Rousseau busca definir um modo próprio de filosofar tendo a natureza como uma espécie de modelo ideal para o estabelecimento da cultura, em especial a filosófica. Fazendo-se, numa ruptura com o espírito cartesiano, um pré-crítico das Luzes o filósofo genebrino associa a natureza aos sentimentos e define a consciência, a voz interior, como guia do ser humano tanto na vida privada quanto na vida pública. Mas aí não temos, contudo, uma aterrissagem no individualismo e no solipsismo, pois essa mesma luz que dirige o indivíduo também orienta a fundação da ordem política idealizada; e essa instituição, oriunda do pacto associativo, se apoia nos ditames da vontade geral garantindo a soberania do povo no seu conjunto.
\end{abstract}

Palavras-chave: Natureza. Homem. Subjetividade. Liberdade. Política.

\begin{abstract}
My purpose in this text is to show, at first, that Rousseau seeks to define a proper way of philosophizing with nature as a kind of ideal model for the establishment of culture, especially the philosophical one. Making himself, in a rupture with the Cartesian spirit, a pre-critic of the Lights, the Genevan philosopher associates nature with feelings and defines the conscience, the inner voice, as the guide of the human being both in private life and in public life. But here we do not have a landing in individualism and solipsism, for that same light that directs the individual also guides the foundation of the idealized political order; and this institution, derived from the associative pact, relies on the dictates of the general will, guaranteeing the sovereignty of the people as a whole.
\end{abstract}

Keywords: Nature. Man. Subjectivity. Freedom. Politics.

A filosofia, este domínio amplo do conhecimento humano, desenvolvido há mais de 25 séculos no mundo ocidental, apresenta muitas entradas e saídas quando resolvemos dela nos aproximar, tomando decisão de indagá-la, interrogá-la. Se por ventura é algo verdadeiro possuindo sentido dizer-se isto que precede, se é cabível apresentar-se semelhante afirmação, nenhum outro filósofo senão J.-J. Rousseau (1712-1778) é passível de encaixar-se tão radicalmente nesse modo de interpretar. Desenvolver-se uma reflexão a partir do genebrino requer que se entenda, notadamente, que ele empreende uma ruptura com os padrões convencionais da escrita filosófica, com os planos delineados tradicionalmente.

Diferencia-o, sobretudo, este fato de redigir livros em que um é uma espécie de complementação do outro, um lança luz sobre o outro, e que é desnecessário levarse em conta de forma rigorosa a cronologia aí estabelecida, podendo-se lê-los então

\footnotetext{
${ }^{1}$ Doutor em Filosofia pela UNICAMP, com estágio pós-doutoral em Filosofia pela PUCRS. Professor da Graduação e Pós-Graduação (Stricto Sensu) em Filosofia da UEL. E-mail: earlei@uel.br.
} 
do começo para o final, mas também de trás para diante sem trazer qualquer prejuízo à compreensão do todo. Por outro lado, e mais importante - no presente momento - do que isso que precede, é que o filósofo não faz questão de definir precisamente seus conceitos. Aliás, o genebrino dá-nos, quase sempre, mais de uma ideia sobre um mesmo termo, sobre uma mesma noção, sem enunciar uma lógica muito precisa para seu sistema filosófico, seu arcabouço teórico. Ele o molda de forma assistemática, sendo conduzido geralmente pelos sentimentos, embora se defenda, ao encontrar espaço, por sempre operar com os mesmos princípios mantendo em todo o tempo o mesmo propósito, conectando-se com o interesse unicamente pela verdade. Inclusive, tal é a divisa que lhe inspira ficando com ela comprometido em qualquer que seja a circunstância. Observe-se o que nos traz o segundo prefácio de Júlia ou A Nova Heloísa (1761): “aquele que prefere a verdade à própria glória pode esperar preferi-la à própria vida. Desejais que se seja sempre consequente, duvido que isso seja possível ao homem, mas o que lhe é possivel é ser sempre verdadeiro: eis o que desejo procurar ser" (OC II, Nouvelle Heloíse, p. 27).

Quanto às incoerências supostas de suas ideias, no âmbito geral de seu pensamento, Rousseau realiza sua defesa ao se tornar alvo de condenação. Está aqui para provar sua carta a Christophe de Beaumont escrita pouco depois de ser publicado o robusto Emílio ou Da educação, o qual gerou ira nas autoridades civis e eclesiásticas pelo conteúdo nele veiculado, capaz mesmo de incomodar quem não aceita uma nova forma de estabelecer-se a filosofia e de enxergar-se efetivamente o mundo. Aí assevera Rousseau:

Escrevi sobre diversos assuntos, mas sempre segundo os mesmos princípios: sempre a mesma moral, a mesma crença, as mesmas máximas, e, se se quiser, as mesmas opiniões. Juízos contraditórios, no entanto, foram feitos sobre meus livros, porque fui julgado pelos assuntos de que tratei muito mais do que por meus sentimentos (OC, IV, p. 40).

Não restam dúvidas de que Rousseau nas suas reflexões prioriza o paradoxo, o alinhamento do par de opostos, as asserções dicotômicas, mesmo que conserve total unidade teórica e que afirme isto que diz no fragmento acima. Ao leitor pode não bastar ter em conta o Discurso sobre a desigualdade, que é desenvolvido a partir de um conjunto de termos dúbios, de ideias controversas, decorrentes da vida concebida enquanto processo, para reconhecer o que acabamos de afirmar. Então, que considere o teor do juízo do Emílio, identificado no livro II, que serve como um referencial concludente em tal sentido, legado pelo filósofo, sendo endereçado àqueles que acompanham sua meditação pouco cartesiana: "perdoai meus paradoxos; é preciso fazê-los quando se reflete; prefiro ainda ser homem de paradoxos do que homem de preconceitos" (OC IV, Émile ou de l'éducation, p. 323). 
Tomando-se aqui enquanto algo dado, não deve nos interessar a fundamentação da ideia de que o filósofo de Genebra é um autor notadamente dialético $^{2}$ que se soma a tantos pensadores modernos, como o são, por exemplo, Montaigne ou Diderot ${ }^{3}$, que buscam robustecer tal tradição. E isto após os esforços propalados na antiguidade, engendrados primeiro com as investidas de Heráclito, e mais tarde por Platão, trazendo o germe, de certa maneira, do pensar dessa mesma natureza florescente na contemporaneidade; este brota, inicialmente, com Hegel e é consumado na reflexão materialista de Marx e Feuerbach, os quais travaram embate com este autor idealista nunca desvalorizado por seu método, mas sim por sua doutrina, vista como um misto de filosofia e de teologia dado ao abstracionismo e às preocupações com o absoluto que o caracterizam. A proposta de Rousseau, de valorizar a contradição, tendo-a enquanto base do pensamento, é para ser algo dado, entendido, portanto, enquanto ponto pacífico, considerando-se ao final suas nuances e desdobramentos próprios.

Antes nos vale perguntar: por que Rousseau opta por este expediente na construção de seu pensamento? Por que ele trabalha dessa maneira? Por certo, não é gratuita essa escolha! Rousseau deseja fazer um tipo próprio de filosofia, levando em conta o que exerce hegemonia na sua época e que não deverá contribuir para ampliar.

Em sentido geral, mesmo que trabalhe com paradoxos e, por outro lado, retenha e expresse a influência de suas fontes de leitura, Rousseau conserva alguns princípios, baseados em certos valores morais, éticos e políticos, que servem de sustentáculo, que desempenham o papel de fundamento de sua filosofia, por assim dizer, naturalista. Semelhantes princípios podem cumprir o papel perfeitamente de suporte metodológico, de ponto de referência, de escala de medida, na apreciação de alguns argumentos com valor ressonante ou oriundo da vida prática ou da prática na vida, tanto partindo da esfera individual quanto do âmbito coletivo.

\footnotetext{
${ }^{2}$ Lido com essa temática no texto "Notas sobre o Emílio de Rousseau e seus aportes para a tradição dialética" que apresentei como comunicação no "XVI Encontro Nacional de Filosofia da ANPOF", realizado em Campos do Jordão/SP entre os dias 27 e 31 de outubro, em 2014.

3 No extenso capítulo XII do Livro II dos Ensaios, intitulado "Apologia de Raimond Sebond", entre as páginas 175 e 312 da edição brasileira, Montaigne dá mostras de alimentar o espírito dialético. Veja-se a passagem seguinte do referido texto: "Em suma, nós mesmos e os objetos, não temos existência constante. Nós, nosso julgamento, e todas as coisas mortais, seguimos uma corrente que nos leva sem cessar de volta ao ponto inicial. De sorte que nada de certo se pode estabelecer entre nós mesmos e o que se situa fora de nós, estando tanto o juiz como o julgado em perpétua transformação e movimento" (MONTAIGNE, Michel de. Ensaios. Trad. de Sérgio Milliet. Porto Alegre: Editora Globo, 1962, Tomo II, p. 310). E segue o autor: "Nada conheceremos de nosso ser, porque tudo o que participa da natureza humana está sempre nascendo ou morrendo, em condições que só dão de nós uma aparência mal definida e obscura; e se procuramos saber o que somos na realidade, é como se quiséssemos segurar a água; quanto mais apertamos o que é fluído, tanto mais deixamos escapar o que pegamos. Por isso, pelo fato de toda coisa estar sujeita à transformação, a razão nada pode apreender na sua busca do que realmente subsiste, pois tudo, ou nasce para a existência e não está inteiramente formado, ou começa a morrer antes de nascer" (Idem, ibidem).
} 
Simpático ao ideal naturalista, Rousseau lamenta no Discurso sobre as ciências e as artes, em mais de um ponto, os efeitos negativos gerados pela intervenção humana na natureza com o desenvolvimento do saber científico e filosófico. A fatalidade é que estávamos no começo dos tempos subordinados, a seu ver, apenas aos imperativos das leis naturais, mas acabamos finalmente sofrendo o domínio exclusivo da arte humana. Com isso: "a elevação e o abaixamento cotidianos das águas do oceano não foram mais regularmente submetidos ao curso do astro que nos ilumina durante a noite” (OC III, Discours sur les sciences et les arts, p. 337).

Essa dinâmica artificial, intermediada com a crescente fomentação e os notórios progressos das ciências e das artes, trouxe de forma gradativa a atenuação da virtude, gerando ao cabo do percurso seu aniquilamento no coração humano. A cada passo em frente impresso pelo saber, ganharam forma, mais e mais, a perniciosidade e a deformação moral do ser humano, consolidando-se o desaparecimento daquele ente puro, simples, e sensível. Argumenta, pois, Rousseau: "viu-se a virtude fugir à medida que sua luz se elevava no nosso horizonte e observouse o mesmo fenômeno em todos os tempos e em todos os lugares" (OC III, Discours sur les sciences et les arts, p. 337).

O saudosismo, sentimento que permeia em larga medida a filosofia de Rousseau, mostra-se muito presente no Primeiro Discurso ${ }^{4}$ quando o autor associa a beleza e a unidade dos costumes ao trabalho desempenhado pela natureza, que cumpre um papel, aliás, tal como se fora a própria providência. Controvertido é que esse panorama sublime parece fadado, entretanto, a não se eternizar no tempo, isolando a chance de podermos apreciar para todo o sempre a simplicidade originária. E semelhante derrocada começa a se anunciar no momento em que o homem deixa a inércia e assume as rédeas das coisas na sociedade.

Ao se tomarem como objeto os costumes e se pensar no que seria o ideal nesse plano, não há como evitar que floresça o sentimento de saudade e de dor pela falta em nosso íntimo, pois aparece a referência àquilo que foi o melhor que se teve na história, sendo moldado pela ação da natureza. Conforme Rousseau: "não se pode refletir sobre os costumes sem se comprazer com a lembrança da imagem da simplicidade dos primeiros tempos. É uma bela praia, ornada unicamente pelas mãos da natureza, para a qual incessantemente se voltam os olhos e da qual com tristeza se sente afastar-se" (OC III, Discours sur les sciences et les arts, p. 22).

Essas considerações, realizadas com base no Discurso sobre as ciências e as artes, nos permitem pensar, logo de início, que Rousseau aceita a ideia de que vige originariamente a sabedoria eterna no mundo dos homens; de que há a realidade concreta da providência como fundamento; de que temos presente a afluência da lei

\footnotetext{
${ }^{4}$ Assim como o Discurso sobre as ciências e as artes é chamado também Primeiro Discurso, O Discurso sobre a origem e os fundamentos da desigualdade entre os homens é conhecido igualmente como Segundo Discurso.
} 
natural, a qual ocupa o posto de diretora de todas as coisas no mundo. Semelhantes máximas, semelhantes princípios teóricos, ora apresentados, marcam presença igualmente, entretanto, no interior, por exemplo, do Discurso sobre a desigualdade. Neste segundo texto, tais princípios, indicadores da viva realidade da lei natural, fazem lembrar, inclusive, a argumentação do próprio De rerum natura de Lucrécio.

Diante da consideração deste último princípio, ao qual cabe a explicação das bases do movimento, convém concluir que os feitos humanos em geral devem ser pensados tendo a natureza como referência, como modelo. Quer dizer, a arte humana, em todos os seus planos, necessita ser desenvolvida tendo o ideal do belo, da harmonia, que a natureza nos traz como uma espécie de critério de medida. Testemos essa ideia ancorando-nos, primeiramente, na esfera da reflexão política de Rousseau. Para tanto, tomemos um exemplo que nos é fornecido pela Dedicatória, texto epistolar do filósofo suíço que serve de introdução ao Segundo Discurso.

Com efeito, sem entrarmos no mérito da veracidade das palavras do autor sob o ponto de vista do que nos informa a pesquisa historiográfica, acessamos uma imagem de Genebra estabelecida por Rousseau, que é pintada como a sociedade ideal. E isso porque conta com uma estrutura jurídica e política equilibrada, bela e harmoniosa, tal como se verifica o ajuste no plano da natureza. Aí tudo aparece combinado, permitindo o favorecimento, dentro daquilo que seria possível, de um caminhar conforme os ditames da lei eterna, encurtando as distâncias existentes entre os homens em termos morais.

Por essa razão, por essa sabedoria aí aplicada, Rousseau sente-se feliz de ser natural de semelhante cidade:

Tendo a felicidade de haver nascido entre vós, como poderia meditar sobre a igualdade que a natureza estabeleceu entre os homens e sobre a desigualdade instituída por eles sem pensar na profunda sabedoria com a qual uma e outra felizmente combinadas neste Estado, concorrem, da maneira mais próxima à lei natural e mais favorável à sociedade, para a manutenção da ordem pública e a felicidade dos particulares? (OC III, Discours sur l'inégalité, p. 111).

Na visão de Rousseau, o respeito e o crédito aos ditames estabelecidos pela sabedoria suprema, aos imperativos determinados pela legislação natural, apresentam-se como uma necessidade aos homens enquanto partícipes da comunidade política. Agindo contrariamente a isso, eles não têm a garantia de se manterem íntegros e de preservarem aquele bem maior que seria sua liberdade. Os governantes em Genebra, de acordo com a Dedicatória, seriam exemplares nesse sentido e ocupariam a posição de "modelo" para os outros corpos políticos existentes: "Alguém dentre vós conhecerá no universo corpo mais íntegro, mais esclarecido, mais respeitável do que o de vossos magistrados? Todos os seus membros 
não vos dão o exemplo de moderação, de simplicidade de costume, de respeito pelas leis e de reconciliação a mais sincera?" (OC III, Discours sur l'inégalité, p. 116)

Com o prefácio do Discurso sobre a desigualdade Rousseau avança introduzindo uma ordem de problemas que não figura no texto da Dedicatória. Essa gama de questões remete-se ao plano do direito natural como uma ciência, visa perseguir os fundamentos dos direitos humanos, alcançar a origem da desigualdade, as fontes do corpo político e tocar o problema da diferença entre a vontade de Deus e a vontade dos homens. Se em tese é ponto pacífico para Rousseau, em primeiro lugar, que a natureza, em sentido amplo, obedece aos ditames da providência, sendo o testemunho da presença de uma razão superior interferindo nas coisas do mundo, isso não resolve o problema específico do direito natural, da liberdade humana.

Para se atingir esse alvo é preciso empreender o afastamento da ignorância que se conserva em relação à natureza originária do homem:

Essa ignorância da natureza do homem é que lança tanta incerteza e obscuridade sobre a definição verdadeira do direito natural, pois, como diz o Sr. Burlamaqui, a ideia do direito e, mais ainda, a do direito natural, são evidentemente ideias relativas à natureza do homem. É, pois, dessa mesma natureza - continua ele - de sua constituição e de seu estado, que se devem deduzir os princípios dessa ciência (OC III, Discours sur l'inégalité, p. 229).

Abrindo mais a perspectiva acima indicada, Rousseau argumenta que o estudo do homem pela via hipotética, com o fito de identificar as necessidades e princípios originais dos deveres humanos, seria o único caminho para se afastar uma série de dificuldades, as quais estariam ligadas ao fundamento da desigualdade moral, às fontes do corpo político, etc.:

\footnotetext{
Esse mesmo estudo do homem original, de suas verdadeiras necessidades e dos princípios fundamentais de seus deveres, representa ainda o único meio que se pode empregar para afastar essa multidão de dificuldades que se apresentam sobre a origem da desigualdade moral, sobre os verdadeiros fundamentos do corpo político, sobre os direitos recíprocos de seus membros e sobre inúmeras questões semelhantes, tão importantes quanto mal esclarecidas (OC III, Discours sur l'inégalité, p. 231).
}

Agora o filósofo acrescenta um dado novo, que nos convida a pensar que a ordem das coisas não emana somente da ação da natureza. Apenas à primeira vista, no julgamento de Rousseau, os estabelecimentos humanos são movidos pelas forças do acaso. Haveria a confluência de fatores estáveis, constantes e regulares, que atuariam silenciosamente na produção da cultura em sentido abrangente, delineando, ao final, suas bases. "Os estabelecimentos humanos parecem, à primeira vista, fundamentados em montões de areia movediça. Só quando os examinamos de perto, só quando removemos o pó e a areia que cobrem o edifício, percebemos a sólida 
base sobre a qual se ergue e se aprende a respeitar os seus fundamentos" (OC III, Discours sur l'inégalité, p. 231).

Apesar de emitir tal juízo, Rousseau entende que o mundo nos apresenta obras que são produto das mãos de Deus e artefatos que resultam, por outro lado, da ação humana. Assim, para resolver esse impasse e afastar a dúvida sobre a fonte que é responsável pelo surgimento de uma determinada produção, não existe outro caminho mais adequado do que estudar seriamente o homem natural, visando identificar suas disposições e suas potencialidades: "ora, sem o estudo sério do homem, de suas faculdades naturais e de seus desenvolvimentos sucessivos, jamais se chegará a fazer essas distinções e, no estado atual das coisas, separar o que a vontade divina fez daquilo que a arte humana pretendeu fazer" (OC III, Discours sur l'inégalité, p. 231). Com semelhante estudo viabiliza-se a chance de se compreender quando um objeto criado pelo ser humano cumpre seu papel, imitando com maestria a perfeição que se apreende nas obras de Deus.

A pesquisa sobre o homem, que não guarda em Rousseau um fim, aliás, em si mesma, mas está conectada a um projeto ético e político idealizado e amplo, representa um núcleo de agregação, de convergência e de fornecimento de impulso aos esforços intelectuais e especulativos do filósofo, vistos na perspectiva da totalidade da obra. Vale observar que Rousseau se abstém, no Primeiro Discurso, de ficar impressionado diante das investigações cosmológicas promovidas pelos homens de ciência, mas indica o que seria mais elevado e mais difícil no âmbito dos estudos: "penetrar em si mesmo para estudar o homem e conhecer sua natureza, seus deveres e seu fim" (OC III, Discours sur les sciences et les arts, p. 334).

No Discurso sobre a desigualdade o filósofo prossegue e afirma que esse saber tanto é importante e pouco avançado até o presente momento como a inscrição identificada no Templo de Delfos - "conhece-te a ti mesmo" - é algo que supera, na história humana, as máximas em geral proferidas pelos moralistas: "O mais útil e o menos avançado de todos os conhecimentos humanos parece-me ser o do homem e ouso afirmar que a simples inscrição do Templo de Delfos continha um preceito mais importante e mais dificil que todos os grossos livros dos moralistas" (OC III, Discours sur l'inégalité, p. 227).

Pertinente assinalar, neste momento, que o plano que informa a investigação sobre o homem no Discurso sobre a desigualdade guarda alguma semelhança com o projeto delineado no Emílio. Como diferenças entre um projeto e outro podemos indicar que o desafio do autor, no primeiro livro, é apreender o homem enquanto espécie, ao passo que a meta no segundo será alcançá-lo enquanto indivíduo. Além disso, no Segundo Discurso o homem é assumido como um dado hipotético e no Emílio transforma-se num aluno de cunho imaginário. 
Em ambos os livros, todavia, colhemos um mesmo princípio epistemológico e ético que norteia a investigação: primeiro, é desejado alcançar o homem em sua bondade natural, em sua pureza primitiva; depois, é cobrado que aquele siga as determinações da natureza em sua vida. Esta última máxima, aliás, orienta com firmeza toda a estruturação teórica do Emílio, exigindo que o preceptor seja conivente para com ela. E isso, sobretudo, quando estiver se relacionando com o ser humano em processo de desenvolvimento, em trabalho de formação:

Observai a natureza e segui o caminho que ela vos indica. Ela exercita continuamente as crianças; ela enrijece seu temperamento mediante experiências de toda espécie; ela ensina-lhes desde cedo o que é pena e dor [...]. Essa a regra da natureza. Por que a contrarias? Não vedes que, pensando corrigi-la, destruís sua obra, impedis o efeito de seus cuidados? Fazer por fora o que ela faz por dentro é, a vosso ver, aumentar o perigo; e, ao contrário, é desviar-se do rumo, é extenuá-lo (OC IV, Émile, p. 259-26o).

Esse ditame central em Rousseau revela seu nexo, sua afinidade, com a tradição especulativa desenvolvida no mundo helenístico e romano. Tudo indica que foi, em particular, de suas leituras de Sêneca que ele extraiu este princípio, pelo qual ao homem são fornecidos a paz, a tranquilidade, e, portanto, o soberano bem na vida social. Nas Cartas a Lucílio, mostrando-se um fiel seguidor do estoicismo, o autor romano argumenta com um tom categórico: "o nosso objetivo é, primacialmente, viver de acordo com a natureza" (SÊNECA, 1991, p. 11). E antes, no opúsculo intitulado Da vida feliz, ele havia afirmado que "uma vida feliz é a que está em conformidade com a natureza" (SÊNECA, 1962, p. 726).

Ao se referir à necessidade de o homem viver de acordo com os imperativos da sabedoria eterna, Sêneca caminha na direção de desenvolver o reconhecimento da subjetividade, destoando da visão que exerce hegemonia dentro da tradição grega clássica. Ao homem reservar-se-ia, desde então, a possibilidade de figurar no ponto de partida, de ser o centro de suas próprias deliberações, de gozar de liberdade e de se fazer um ser autônomo.

Naquele momento em que Sêneca indicou, por outro lado, que a atitude de voltar à natureza significava o gesto do homem de ouvir os ditames de sua razão, estava vislumbrando nessa faculdade a essência mesma do ser humano. E tinha-se aí um salutar e pioneiro esforço de reconhecimento do fórum íntimo do sujeito, mesmo que se veja neste ato uma limitação, quando percebemos um certo esforço em estreitar a vida interior e individual, prendendo-a na dimensão estrita da racionalidade.

Esse pensamento de cunho subjetivista e racionalista aparece também na base da filosofia de Descartes no mundo moderno. Fazendo uso de um método de pesquisa que se pretende rigoroso e tendo interesse de conservar o homem no 
centro da produção humana e do trabalho especulativo, o autor francês do século XVII associa a natureza à razão, identifica a essência do homem com o pensamento. Com a abertura e a radicalização de tal perspectiva, que influencia os especuladores vinculados ao círculo enciclopédico, os quais contam com Diderot e com d'Alembert à frente, o natural define-se como aquilo que aparece materializado; revela-se como o dado objetivo identificado no mundo externo, passível de quantificação, de mensuração, que se transforma enfim em objeto de estudo das ciências.

Rousseau, com seu empenho autodidata aplicado em seu desenvolvimento intelectual e filosófico, tirou proveito de seu contato com os livros tanto de Sêneca como de Descartes, retendo os saberes que julgava dignos de serem apreendidos. São muitos esses saberes, os quais, no caso de Sêneca, relacionam-se, sobretudo, com o âmbito da antropologia, da ética e da filosofia da história. E no que tange a Descartes, prende-se mais, em sentido amplo, ao procedimento metodológico, cujo sentido reside, aliás, em garantir a absorção de ideias passíveis de serem julgadas evidentes e distintas.

Mais do que esses fatores gerais, contudo, precisamos considerar que Rousseau assegura, de certo modo, sua fidelidade para com a tradição inaugurada pela filosofia helenística e levada adiante pelos modernos - isso desde os teóricos do Renascimento até seu ápice com Descartes no século XVII. Assim, ele conserva a subjetividade no lugar de base e de ponto de partida de todo o progresso da cultura, fazendo-a um centro maior e um núcleo irradiador do exercício especulativo. Mas há o ponto nevrálgico, entretanto, do afastamento do autor genebrino em relação a essa tradição, o qual reside na maneira como concebe a interioridade humana, dada especificamente a sua forma distinta de compreender a natureza. É daí que se vão puxar e extrair elementos que justificam, ao final, o fato de Rousseau ser julgado um pré-crítico das Luzes e um romântico.

Incomodado com a redução, o estreitamento, do ser humano promovido pelas filosofias racionalistas e intelectualistas, Rousseau associa o plano interno do homem à esfera do sentimento, a qual definiria a substantividade da consciência, colocada numa perspectiva estrutural diametralmente oposta à concepção cartesiana. Tem-se, a partir dessa oportunidade, uma natureza que surge associada aos sentidos e vê-se emergir uma nova concepção de homem em seu primeiro movimento constituinte enquanto ser. $\mathrm{O}$ ser humano, estabelecido como um conceito, mantém uma dinâmica caracterizada, basicamente, por sentir antes de pensar. Haveríamos de encontrar aí, nessa esfera do sensível, o lugar verdadeiro do fundamento, do dado originário, do fenômeno de cunho imediato, espontâneo, intuitivo, que não seria decorrente, pois, da reflexão. ${ }^{5}$

\footnotetext{
5 Veja-se o texto de Derathé intitulado O racionalismo de Rousseau, na nota de número 81, onde ele explica porque Rousseau define a consciência como sentimento fundamentando no que ela se diferenciaria da racionalidade.
} 
Rousseau mostra, nos Devaneios do caminhante solitário, o significado contido no ato de o ser humano se desprender do mundo externo e ficar em contato unicamente consigo mesmo, formando algo que se traduz pela mais perfeita unidade. Nesse momento histórico aparece o ser que se faz soberano, autossuficiente e insuperável enquanto um ente inserido na esfera social: "de que desfrutamos numa tal situação? De nada de exterior a nós, de nada a não ser de nós mesmos e de nossa própria existência; enquanto este estado dura bastamo-nos a nós mesmos como Deus" (OC I, Les rêveries, p. 1047).

Rousseau considera mesmo haver essa precedência dos sentimentos e dos atos da consciência nos trabalhos espirituais mais primitivos do ser humano em seu íntimo: "Sentimos antes de conhecermos [...]. Os atos da consciência não são julgamentos e sim sentimentos" (OC IV, Émile, p. 599). Seriam esses dados internos os detentores do poder de revelar ao mundo um ente isento de suas próprias mãos ou mesmo do percurso civilizatório ou histórico. Neles Rousseau vê a fonte não apenas da verdade no sentido metafísico e lugar de armazenamento dos preceitos referenciais ideais ao agir humano absolutamente acertado, mas também o núcleo de retenção dos valores estéticos absolutos e incontestáveis. Em síntese, para Rousseau, "embora todas as nossas idéias nos venham de fora, os sentimentos que as apreciam estão dentro de nós e é unicamente por eles que conhecemos a conveniência ou a inconveniência que existe entre nós e as coisas que devemos respeitar ou evitar" (OC IV, Émile, p. 599).

Certo de que a natureza, no caso do homem, associa-se aos sentimentos, o filósofo genebrino conclama que o ser humano atente aos ditames por eles estabelecidos. A Jacob Vernes Rousseau escreve numa carta, em 1758, com um tom imperativo: "consultei a natureza, isto é, o sentimento interior, que dirige a minha crença, independentemente de minha razão" (Lettres philosophiques, 1974, p. 54).

Com esse chamado do sujeito à consciência, ao sentimento interior, Rousseau postula solucionar uma parte importante de sua problemática teórica, pois entende que consegue livrar e proteger o homem de toda a determinação produzida pelo mundo externo. Ouvindo a voz que palpita e que se dissemina em seu íntimo, o ser humano, segundo Rousseau, revela-se tal qual o fez a natureza e encontra a mais absoluta liberdade.

Convém dar atenção agora à estratégia indicada por Rousseau como via para se acessar o âmbito da interioridade humana, que implica, aliás, uma recusa da visão intelectualista hegemônica em sua época. Os contemporâneos do pensador de Genebra, em especial os Enciclopedistas, são defensores da tese de que deve haver desenvolvimento da razão, advento de mais e mais progresso científico e tecnológico, pois identificam o bem-estar e a satisfação humana em sua plenitude como algo que se vincula ao acúmulo ininterrupto de novos conhecimentos. Esse 
seria o caminho que conduziria o homem, segundo eles, ao contato consigo mesmo e que permitiria, por conseguinte, retomar-se a ordem da natureza na sociedade.

Rousseau considera, de sua parte, que o comportamento humano recomendável, com a consequente harmonia deste último consigo mesmo, não requer, contrariamente ao que pensam seus adversários e interlocutores, o gasto de tempo com pesquisas científicas e com meditações filosóficas. O que precisa existir, em verdade, é a disposição do sujeito em voltar-se a si mesmo e ouvir a voz de sua consciência, de seu sentimento interior. É assim que o indivíduo tem possibilidades de contatar seu "eu" profundo e apreender o sentido que a vida como um todo de fato possui. Por tal ato simples de retornar à sua esfera íntima, esse é levado ao caminho que o conduz a desvelar os mistérios e conhecer as regras ditadas pela sabedoria eterna.

Semelhante acontecimento se processa quando, com aquela referida conduta remissiva, ele promove a neutralização de suas paixões, mostrando-se disposto, por fim, a realmente se escutar. Esse ato simples, marcado por ser introspectivo, que o coloca em conformidade com a ordem eterna e que se constitui em muito boa filosofia, é algo que dispensa a posse de um grande volume de conhecimentos:

Oh! Virtude, ciência sublime das almas simples, serão necessários, então tanta pena e tanto aparato para conhecer-te? Teus princípios não estão gravados em todos os corações? E não bastará, para apreender tuas leis, voltar-se sobre si mesmo e ouvir a voz da consciência no silêncio das paixões? Aí está a verdadeira filosofia (OC III, Discours sur les sciences et les arts, p. 30).

Assim como Rousseau considera que o pensamento modelo se revela por meio daquela conduta espontânea, marcada pela simplicidade, que é acessível a qualquer ser humano interessado em empregá-la, não deixa de indicar que o reconhecimento da voz interior pelo indivíduo necessita ser tratado como um ditame. São muitos os extratos que se podem considerar, em sua extensa e variada obra, que possuem semelhante conotação. A título ilustrativo, observemos o caráter de suas palavras dirigidas ao público na Dedicatória à República de Genebra: “conjuro-vos a que penetreis todos o fundo de vosso coração e consulteis a voz secreta de vossa consciência" (OC III, Discours sur l'inégalité, p. 116).

Não se exagera ao indicar no que consiste, para Rousseau, a representatividade da consciência, do sentimento interior, para a vida humana em sociedade, além de já sabermos que nela habitam os dados originários. Façamos isso recorrendo ao texto da "Profissão de fé do vigário saboiano", inserido no livro IV do Emílio, que às vezes parece ser um escrito autônomo, independente, algo à parte, no interior do "grande tratado". Nesse escrito, onde o filósofo ou formula as bases de sua ética ou as consuma, dependendo do modo como o julguemos, e também apresenta 
reflexões críticas, por exemplo, sobre coisas como religião, educação e política, vemos a consciência ser tomada como um guia sublime que dirige o homem, conservando-o na ordem da natureza: "Consciência! Consciência! Instinto divino, voz celeste e imortal; guia seguro de um ser ignorante e limitado, mas inteligente e livre; juiz infalível do bem e do mal, que tornas o homem semelhante a Deus" (OC IV, Émile, p. 60o-601).

Munido dessa faculdade sublime, o homem termina fazendo-se superior aos bichos, que realizam seus movimentos mecanicamente; ademais, dispondo-se a segui-la em seu trajeto, cheio de obstáculos, ele conta com a certeza de que não irá se perder, de que não irá se extraviar: "és tu que fazes a excelência de sua natureza e a moralidade de suas ações, sem ti nada sinto em mim que me eleve acima dos bichos, a não ser o triste privilégio de me perder de erro em erro com a ajuda de um entendimento sem regra e de uma razão sem princípios" (OC IV, Émile, p. 601).

Rousseau considera que seguir a voz interior, obedecer aos imperativos da consciência, não significa para o sujeito subordinar-se aos ditames de suas inclinações, de seus desejos efêmeros e de seus vícios, que representam elementos perfeitamente capazes de lhe conduzir ao desregramento e à perdição. Com os raciocínios de $A$ Nova Heloísa Rousseau mostra que por detrás dos homens, no fundo, habita o autor de todas as coisas, o qual os orienta para que não se extraviem e contribui, igualmente, para que não percam algo tão precioso como é a humildade. Deus lhes impõe um fim nobre e lhes garante, em suma, um estado elevado espiritualmente, um estado confortável.

Atento à sua presença em seu íntimo, o homem busca compreender os mistérios maiores da natureza, resignando-se quando não lhe é permitido acessar a todo o saber que gostaria de dispor. Além disso, faz-se um ser moral, pois sua conduta coloca-o em consonância com a ordem, revelando a sintonia de seus atos com o seu dever: "Aquele que reconhece e serve o pai comum dos homens crê ter uma mais alta destinação, o ardor de preenchê-la anima seu zelo e, seguindo uma regra mais segura do que suas inclinações, sabe fazer o bem que lhe custa e sacrificar os desejos de seu coração à lei do dever" (OC II, La Nouvelle Héloïse, p. 363).

A ruptura da harmonia com o supremo artífice acontece quando o ser humano reluta em escutar ou ousa a fazer-se indiferente à voz de sua consciência, de seu sentimento interior. Essa transgressão, além de afastar o sujeito da verdade e de todo o ideal, produz o desconforto e impõe a si mesmo o peso da culpa e do remorso. Mas a providência, durante o tempo em que este se conserva íntegro e saudável, previne a desordem, conduzindo-o a viver o temor de ser acometido pelos citados sentimentos negativos, notadamente terríveis e torturantes. Observemos que Júlia, personagem central de A Nova Heloísa, revela-se grata à sabedoria eterna, pois é devido à sua intervenção que ela se mantém na ordem moral: "O autor de toda a verdade absolutamente não consentiu que eu saísse de sua presença culpada de 
um vil perjúrio e, prevenindo meu crime por meus remorsos, mostrou-me o abismo em que ia precipitar-me" (OC II, La Nouvelle Héloïse, p. 356).

Pensando no problema da dificuldade de a voz interior ser reconhecida pelos homens, o filósofo genebrino encontra espaço, no romance acima citado para reforçar sua visão negativa em relação ao conceito de homem e de natureza que resulta dos esforços racionalistas e intelectualistas. Ao final terminamos por observar que ele rebaixa o valor do trabalho intelectivo e reflexivo, pois duvida do poder, em verdade, que carregam os simples argumentos. No juízo de Rousseau, o ser humano, no momento em que medita e que constrói proposições, contribui para desprezar e aviltar a virtude, posto que é conduzido para fora de si mesmo.

Rousseau, enquanto os outros filósofos das Luzes veem semelhantes práticas como imprescindíveis, para o homem conquistar a liberdade, as considera, portanto, como atividades espirituais e teóricas decisivas no seu processo de desnaturação.

Não te lembrarei estes argumentos sutis que tu me ensinaste a desprezar, que enchem tantos livros e que nunca fizeram um homem honesto. Ah! Estes tristes raciocinadores, nunca os seus corações sentiram ou fizeram sentir estas doces alegrias! Deixa, amigo, esses moralistas fátuos e volta ao recôndito de tua alma; é aí que verás este eterno simulacro do verdadeiro belo, cuja contemplação nos anima com um entusiasmo santo e que as nossas paixões aviltam sem cessar, sem que, todavia, a possa apagar (OC II, La Nouvelle Héloïse, p. 223).

Desenvolvendo tal gênero de raciocínio, Rousseau lança as bases de um pensamento original e formador de uma ruptura com as concepções filosóficas que exercem supremacia no século XVIII. Porém, ele não deixa de fazer parte do rol dos filósofos que representam a Época das Luzes, não se torna absolutamente estranho ao projeto de seu século que visa à emancipação humana. Nele temos, notadamente, uma interessante invenção, um curioso engenho: Rousseau possibilita-nos aspirar medir, se contarmos com os elementos apresentados até aqui como uma espécie de quadro de referência ideal, o grau de proximidade ou de distanciamento que a cultura, como um todo, possui diante do modelo. Logo, mais central talvez que outras indicações é assinalar que todos os âmbitos do pensamento de Rousseau, incluindo o campo da reflexão moral, ética e política, aparecem moldados pelo ideal de beleza que traz como referência o ordenamento eterno, criado pela natureza, que serve como uma espécie de imperativo categórico. Seriam os ditames naturais, entendidos enquanto providentes e divinos, que cumpririam a função de núcleo regulador do sistema do mundo, seriam os princípios estabelecidos por esta última que constituiriam, sendo postos como fonte de inspiração da arte humana, a esfera modelar e modeladora. Por esse motivo, o filósofo mantém, em síntese, que "o que está fora da natureza não nos toca” (OC V, Lettre sur la musique française, p. 307). 
Rousseau, considerando esta linha ampla de raciocínio, preserva sua filosofia como uma unidade em que tudo é entrelaçado teoricamente, no ponto em que todas as esferas da reflexão podem lançar luzes luminosas umas sobre as outras. Com isso, somos desautorizados de apreciar sejam quais ideias forem, no conjunto da filosofia rousseauniana, como algo em separado, isolado. Devido a isso, nós seguimos a busca de alguns dos seus princípios éticos e políticos perpassando várias de suas obras até chegarmos no plano onde nos encontramos.

O genebrino se interessa por uma base filosófica ética e política abstrata e idealista, mas esse gosto expressivo passa pela pesagem e pela recusa do que é feito neste âmbito na época das luzes. Vê-se assim, de um lado, a realidade concreta, e nesta contamos com o mundo degradado e caótico, promovido em especial por um poder político ilegítimo, que surgiu em razão da ruptura com o direito natural, consumando aquele fatídico ato de usurpação. Mas, de outro lado, surge o discurso abstrato, metafísico, próximo de uma argumentação teológica, em que vislumbramos o panorama da bondade natural, o quadro bem ordenado, conivente com os ditames da providência; aparece o homem sensível, tomado pelo desejo de gozar do sentimento de sua existência, de seguir sempre os imperativos estabelecidos pela sua voz interior.

Podemos notar que as críticas de Rousseau sempre se justificam pela condenação que ele faz do artifício, pela defesa que ele realiza da expressão da vida, da conservação da espontaneidade e da simplicidade, e pelo desprezo, enfim, esboçado diante do esforço insistente de negar-se o natural nas produções humanas.

Digamos, visando concluir a presente reflexão, que a ética e a política ideal, inseridas no eixo da natureza, seriam governadas ao cabo do percurso pela "voz interior" dos indivíduos, pelos "ditames da consciência", enfim, pela "virtude" esta "ciência sublime das almas simples", capaz de impulsionar a "vontade geral" cuja referência é estabelecida em Do contrato social retirando a suspeita, efetivamente, de que a filosofia rousseauniana clama por um atroz solipsismo do sujeito, por um individualismo condenável. A orientação oposta, o agir humano contrário a esses princípios morais, tenderia a manter o quadro desordenado na esfera pública e social sem deixar a esperança de podermos o neutralizar objetivando extingui-lo.

\section{Referências}

BAYER, R. História da estética. Trad. José Saramago. Lisboa: Editorial Estampa, 1979.

CASSIRER, E. A filosofia do iluminismo. Trad. Álvaro Cabral. 2 ed. Campinas-SP:

Editora da Unicamp, 1994.

DERATHÉ, R. Le rationalisme de Jean-Jacques Rousseau. Paris: PUF, 1948. 
GRIMSLEY, R. La filosofía de Rousseau. Trad. Josefina Rubio. Madrid: Alianza Editorial, 1993.

GROSRICHARD, A. “A ópera de Rousseau”. In.: NOVAES, Adauto (org.). Arte pensamento. São Paulo: Companhia das Letras, 1994.

LUCRÈCE. De la nature. Trad. Alfred Ernout. 2 ed, v.2, Paris: Les Belles Lettres, 1997.

OLIVIER, P. Introductions [Lettre sur la musique française]. In.: ROUSSEAU, J.-J.

Oeuvres Complètes. v.5, Paris: Gallimard, 1995 (Bibliotèque de la Pléiade).

ROUSSEAU, J-J. Discours sur les sciences et les arts. Oeuvres Complètes, v.3, Paris: Gallimard, 1964 (Bibliotèque de la Pléiade).

. Narcisse ou l'amant de lui-même. Oeuvres Complètes, v.2, Paris: Gallimard, 1964 (Bibliotèque de la Pléiade).

. Discours sur l'origine et les fondements de l'inégalité parmi les hommes.

Oeuvres Complètes, v.3, Paris: Gallimard, 1964 (Bibliotèque de la Pléiade).

. La Nouvelle Héloïse. Oeuvres Complètes. v.2, Paris: Gallimard, 1964

(Bibliotèque de la Pléiade).

Lettre sur la musique française. Oeuvres Complètes. v.5, Paris: Gallimard, 1995 (Bibliotèque de la Pléiade).

. Essai sur l'origine des langues. Oeuvres Complètes. v.5, Paris: Gallimard, 1995 (Bibliotèque de la Pléiade).

. Émile ou de l'éducation. Oeuvres Complètes, v.4, Paris: Gallimard, 1969

(Bibliotèque de la Pléiade).

. Les revêries du promeneur solitaire. Oeuvres Complètes, v.1, Paris: Gallimard, 1959 (Bibliotèque de la Pléiade).

. Lettres philosophiques, ed. Henri Gouhier. Paris: Vrin, 1974.

SÊNECA. Cartas a Lucílio. Trad. J. A. Segurado e Campos. Lisboa: Fundação

Calouste Gulbenkian, 1991.

. De la vie heureuse. Trad. Émile Bréhier. In.: Les Stoïciens, v.2. Paris:

Gallimard, 1962.

STAROBINSKI, J. Introductions [Essai sur l'origine des langues]. In.: ROUSSEAU, J.J. Oeuvres Complètes, v.5, Paris: Gallimard, 1995 (Bibliotèque de la Pléiade).

Submissão: 30.08.2017 / Aceite: 16. 09. 2017 